\title{
Possibilidades identitárias contemporâneas em um mundo do trabalho flexibilizado
}

\author{
Possibilities of identity in a contemporary world of work more flexible \\ Posibilidades de la identidad en un mundo contemporáneo de trabajo más flexibilizado
}

\section{Marcelo Afonso Ribeiro}

Universidade de São Paulo, São Paulo, SP, Brasil.

Maria Conceição Coropos Uvaldo

Universidade de São Paulo, São Paulo, SP, Brasil.

\section{Resumo}

A identidade surgiu como uma categoria que definiria o lugar psicossocial das pessoas pela adaptação a uma estrutura sociolaboral hegemônica predefinida (outro generalizado). Com as mudanças gradativas da contemporaneidade geradoras de estruturas sociolaborais mais instáveis e flexíveis (outros generalizados), a identidade deixou de ser somente um processo de adaptação para se tornar um processo de construção contínua. Tomando como base a dimensão do trabalho, o presente ensaio teórico teve como objetivo organizar as alternativas atuais de construções identitárias por aproximações conceituais possíveis entre cinco pensadores (Alain Touraine, Claude Dubar, Manuel Castells, Robert Castel e Stuart Hall), resultando em quatro categorias: nostalgia, fechamento, instrumentalidade e possibilidade. Concluindo, o momento atual é de transição, pois estruturaria dois caminhos identitários distintos: um baseado num processo mais definido e estável de adaptação (categorias do fechamento e da nostalgia) e outro baseado num processo de construção relacional contínua (categorias da possibilidade e da instrumentalidade).

Palavras-chave: Trabalho, Identidade, Flexibilização, Contemporaneidade, Projeto de Vida.

\section{Resumen}

La identidad surgió como categoría que definiría la situación psicosocial de las personas, a través de su adaptación a la estructura socio-ocupacional hegemónica (otro generalizado). Los cambios contemporáneos graduales han generado estructuras sociales más flexibles (otros 
generalizados) y la identidad ha dejado de ser sólo un proceso de adaptación para convertirse en un proceso continuo de construcción. Basado en el trabajo, este ensayo teórico tuvo como objetivo organizar las posibilidades actuales para las construcciones de identidad, a través de las relaciones conceptuales entre cinco pensadores (Touraine, Dubar, Castells, Castel y Hall). Los resultados indicaron cuatro categorías: nostalgia, enclaustramiento, instrumentalidad y posibilidad. En conclusión, el tiempo presente se define por una transición, y ha estructurado dos maneras diferentes para la construcción de la identidad: una basada en un proceso más estable, que es la adaptación (enclaustramiento y nostalgia), y otra basada en un proceso continuo de construcción relacional (posibilidad e instrumentalidad).

Palabras-clave: Trabajo, Identidad, Flexibilización, Contemporaneidad, Proyecto de Vida.

\begin{abstract}
Identity emerged as a category that would define the psychosocial status of people by an adaptation to a socio-occupational hegemonic structure (generalized other). With the gradual changes of the contemporaneity that has left the social structures more flexible and unstable (generalized others), identity has ceased to be only an adaptation process to become a continuous process of construction. Based on labor, the present theoretical essay aimed to organize the current alternatives of identity constructions through possible conceptual interrelation among five researchers (Alain Touraine, Claude Dubar, Manuel Castells, Robert Castel and Stuart Hall). The results pointed out four identity categories: nostalgia, enclosure, instrumentality and possibility. In conclusion, the present is defined by a transition, that has structured two different ways for the identity construction: one based on a more defined and stable process of adaptation (enclosure and nostalgia) and another based on a continuous process of relational construction (possibility and instrumentality).
\end{abstract}

Keywords: Labor, Identity, Flexibilization, Contemporaneity; life project.

\section{Introdução}

Fischer (1996) aponta que a identidade se configura como uma ideiasíntese que exprime a resultante das relações complexas entre pessoa, outros e sociedade (dimensão psicológica e social: EU-OUTRO), numa articulação da diferença e da igualdade numa mesma pessoa em relação a si mesma e ao outro, que permitiria o autoconhecimento (eu), o reconhecimento (pertença social) e as trocas sociais ou intersubjetividade (implicação social).

O trabalho é uma das referências ontológicas fundantes da humanidade, 
sendo uma dimensão fundamental para a construção identitária, subjetiva e dos projetos de vida no trabalho (Antunes, 1999; Lukács, 1980). Ao longo de boa parte do século $\mathrm{XX}$, o mundo moderno ofereceu padrões mais estáveis e previsíveis para a construção do projeto de vida no trabalho, baseados em critérios uniformes e homogêneos que, se por um lado dificultavam transformações no mundo do trabalho, por outro traziam segurança e possibilidade de planejamento do futuro (Blanch, 2003; Castel, 1999). Era um mundo constituído de referentes absolutos (outro generalizado, conforme postulou Mead, 1953), que ditavam a ordem das coisas numa estrutura permanente e estável de posições às quais as pessoas deveriam se adaptar, fabricando a si mesmas e seu cotidiano pela reprodução de um mundo conhecido (Certeau, 1994; Guichard, 2000; Lallement, 2007; Pelletier, 2001).

Neste contexto, segundo Barbier (1996), a identidade seria um projeto de estado, ou seja, uma representação relativa ao estado final (realidade transformada) do que se pretende transformar, constituindose numa antecipação de um estado: a identidade seria, então, um produto a ser conhecido e alcançado - uma conformação do ser social baseado em modelos vigentes, que geraria equilíbrio como resultante da relação pessoa e trabalho, produtor de permanência.

A identidade ocupacional e/ou profissional se construía tendo como referentes a categoria profissional ou ocupacional a qual a pessoa estava vinculada, gerando construções identitárias semelhantes e potenciadoras de constituição de grupos de pares, que viviam e lutavam pelas mesmas bandeiras e com as mesmas estratégias (Sainsaulieu, 1988).

Com as mudanças sociolaborais iniciadas ao longo da década de 1970 e que atingiram de forma mais marcante a realidade brasileira durante os anos 1990, os padrões para construção da identidade e do projeto de vida no trabalho se tornaram mais instáveis, complexos e heterogêneos, pela emergência de uma multiplicidade de referentes e critérios para guiar a vida no mundo (Coutinho, 2009; Coutinho, Krawulski \& Soares, 2007; Dubar, 2000; Guichard, 2000; Touraine, 1998), pois a referência hegemônica do outro generalizado (Mead, 1953), deu espaço para a emergência de múltiplas referências de outros generalizados (Malo, 2007).

Se, antes, a identidade era um projeto de estado realizado pela adaptação a uma ordem sociolaboral predefinida, agora ela se torna um projeto de ação (Barbier, 1996), determinado pela construção num mundo em transformação, 
no qual não há modelos hegemônicos com produtos finais (estados) a serem alcançados, restando à pessoa centrar seus esforços identitários na construção de um percurso a partir de indicações de possíveis processos e caminhos, como sínteses temporárias, não definitivas (produtora de mudança) e, por isso, trazendo mais insegurança ontológica: como criar referência num mundo em constante transformação? O mundo contemporâneo tem oferecido espaço para referentes identitários mais estáveis, geradores de reprodução e permanência, mas também para referentes identitários mais instáveis, geradores de construções sucessivas e mudança constante.

Tomando por base a dimensão trabalho, o presente ensaio teórico teve como objetivo organizar as alternativas atuais de construções identitárias, através da realização de aproximações conceituais possíveis entre cinco pensadores contemporâneos: Alain Touraine, Claude Dubar, Manuel Castells, Robert Castel e Stuart Hall.

\section{Contemporaneidade, formas identitárias e trabalho}

Para Castells (1997) e Touraine (1998), há três posições políticas por parte das pessoas diante de um futuro que se mostra instável: a) Tentativa do retorno a controles sociais mais hegemônicos, numa volta aos modelos passados, mas com controles normativos mais rígidos;

b) Tentativa de navegar numa situação de falta de controle utilizando pistas intermitentes do social, entretanto sem uma referência clara a seguir;

c) Tentativa de criar referência num mundo em constante transformação pela construção gradativa de projetos de ação, geradores de uma organização espaço-temporal mais pessoal $\mathrm{e}$ temporária, com o estabelecimento de espaços legíveis ao outro enquanto projetos legitimados socialmente.

Para Demazière e Dubar (2006), a idéia tradicional da identidade, como produto coletivo determinado pela identificação com o outro generalizado hegemônico, requisita um mundo social mais estável e normativo, no qual há poucas formas de transformação e gera pessoas mais semelhantes. Num mundo instável e flexível, os autores apontam que a estruturação identitária também se torna mais instável e flexível, rompendo com modelos coletivos. Postulam que a identidade não seria um produto antecipável, mas uma resultante, não previsível, gerada pela articulação de dois processos heterogêneos: o processo relacional e o processo biográfico. 
Se, antes, a identidade era gerada a partir de duas estruturações mais estáveis tomadas como produtos (pessoa $\mathrm{e}$ sociedade / EU e OUTRO), Demazière e Dubar (2006) apontam que, num mundo em mudança constante, a identidade também se torna mais complexa e heterogênea e deve ser vista como formas identitárias (temporárias e mais singulares), construídas na relação entre dois processos (relacional e biográfico), conforme se pode ver na Tabela 1 (em anexo) (adaptado de Dubar, 1997, p. 109).

a) Processo relacional: calcado na identidade para o outro (dimensão social), ou seja, a dimensão da identidade destinada ao outro, que é gerada na transação entre a identidade atribuída pelo outro e a identidade assumida pela pessoa, e resultando no reconhecimento ou nãoreconhecimento sociolaboral (identificação ou não com as instituições sociais);

b) Processo biográfico: calcado na identidade para si (dimensão psicológica), ou seja, a dimensão da identidade destinada a si, que é gerada na transação entre a identidade herdada da tradição social e a identidade visada pelo projeto de vida pessoal, e resultando na reprodução sociolaboral (continuidade identitária) ou produção sociolaboral (ruptura e novas construções identitárias), marcadas pela possibilidade ou não de fazer escolhas.
Demazière e Dubar (2006), concordando com Castells (1997) e Touraine (1998), constataram em suas pesquisas recentes acerca das formas identitárias construídas pelos trabalhadores, que eles têm recorrido a duas posturas diante da situação sociolaboral:

a) Fechamento: busca de proteção através do ensimesmamento em grupos profissionais ou nos seus respectivos ofícios, nas chamadas formas comunitárias como base para a construção identitária;

b) Relação: busca de estratégias de interação e vinculação ao atual mundo sociolaboral, seja pela tentativa de manutenção da ordem anterior (sistema de emprego, por exemplo), seja pela tentativa constante de criar e recriar novas maneiras de vínculo e ação sobre e no mundo, nas chamadas formas societárias como base para a construção identitária.

As formas comunitárias são "relações sociais que são fundadas sobre o sentimento subjetivo de pertencer a um mesmo coletivo" (Dubar, 2000, p. 29), de viver a experiência de pertencimento e sua consequente proteção e segurança; enquanto que as formas societárias são relações sociais que são fundadas sobre o compromisso mútuo entre pessoa e sociedade, que se focam mais nas possibilidades relacionais abertas do que no ensimesmamento em um coletivo 
protetor. A primeira forma busca a comunicação e a relação entre iguais, já a segunda visa uma ampliação comunicativa e relacional. Por exemplo: um trabalhador guiado por formas comunitárias se fecha no seu grupo de referência (sindicato ou associação profissional), enquanto que, se for orientado por formas societárias, se abre e se relaciona com o mundo do trabalho como um todo (Dubar, 2000).

A Tabela 2 (em anexo) estrutura esta tese, apontando as formas identitárias ocupacionais e profissionais contemporâneas, segundo Dubar e Demazière (2006).

Dubar e Demazière (2006) definem cada forma identitária da seguinte maneira:

a) Forma estatutária: privilegia a inscrição em um sistema sociolaboral reconhecido, que traga pertença social, estabilidade e segurança, calcada numa dependência institucional. A transação entre o processo relacional e o biográfico se alimenta reciprocamente por conta de um referencial institucional comum;

b) Forma narrativa: tem como marca o predomínio do processo biográfico que privilegia a incerteza de um projeto sobre a segurança da dependência institucional, e se constrói disperso numa rede social não institucionalizada;

c) Forma reflexiva: privilegia o processo relacional através da identificação a um grupo de referência (tipo comunitário) e do apoio numa autoridade, o que proporciona uma socialização integrativa pela interiorização dos valores coletivos;

d) Forma cultural: busca e valoriza o pertencimento a uma comunidade protetora (oficialmente identificada), como forma de resistir às ameaças e incertezas sofridas nos processos identitários;

e) Difusão adaptativa: adaptação a uma situação sociolaboral de incertezas, através de relações sociais de descompromisso e sem projetos futuros, minando qualquer possibilidade de integração espaço-temporal.

Para Dubar (2000), há uma crise da antiga conformação das identidades, que se definiam por formas identitárias culturais e institucionais (forma societária estatutária, forma comunitária reflexiva e forma comunitária cultural); e a mudança gradativa, sem substituição total, para a configuração de formas identitárias que repousam mais em identificações narrativas e adaptativas (forma societária narrativa e forma de difusão adaptativa).

Diante desse quadro, as pessoas teriam maior possibilidade de construção identitária com características menos estáveis, permanentes e genéricas, o que gerou uma mudança nos processos de construção das relações sociais com a relativização do absoluto normativo 
moderno e permitiu transformações, entretanto deixou a pessoa mais isolada num processo de passagem de pessoas assujeitadas (protegidas) para pessoas atoras (expostas e sozinhas) com consequiente predomínio de projetos mais individualizados do que coletivos, posicionando as pessoas em um continuum entre a identidade (modernidade) e difusão (contemporaneidade).

Não é um triunfo da pessoa sobre o coletivo, mas de processos de construção identitários mais focados nas pessoas do que no social, por conta da fragmentação e heterogeneização dos padrões de referência. Assim, a situação atual faz com que as pessoas procurem se localizar em um continuum entre duas posições distintas em relação ao mundo:

a) Nostalgia do passado: busca de proteção nas referências anteriormente constituídas e conhecidas que, se não permitem muita ação no mundo, trazem segurança e estabilidade (forma societária estatutária, forma comunitária reflexiva e forma comunitária cultural);

b) Mergulho no futuro: jogo num campo instável, no qual se aprende constantemente a construir estratégias (forma societária narrativa), tendo chance de mudança social; ou vida no isolamento, sem referências e sujeito a adaptações gradativas, na qual não se escolhe, nem se engaja numa situação de difusão adaptativa
(Kraus, 1998; Marcia, 1966), que não gera permanência, nem constrói história, causando um processo de desidentidade (Touraine, 2001).

Santos (1995), corroborando esta dualidade entre nostalgia e incerteza futura, diz que a relação entre o "moderno e o pós-moderno é, pois, uma relação contraditória. Não é de ruptura total como querem alguns, nem de linear continuidade como querem outros. É uma situação de transição em que há momentos de ruptura e momentos de continuidade" (p. 103).

Tomando como base a colocação de Santos (1995), o quadro descrito por Demazière e Dubar (2006), e ampliando a discussão para outros autores atuais, como Alain Touraine, Manuel Castells, Robert Castel e Stuart Hall, será realizada uma reflexão sobre as possibilidades de construções identitárias na contemporaneidade.

\section{Construções identitárias na contemporaneidade}

\section{Manuel Castells}

Castells (1997) tenta entender como as pessoas têm se posicionado diante de um mundo cada vez mais instável, flexível e heterogêneo, através da (re) construção de suas identidades, sempre uma construção marcada por relações de poder. Segundo o autor, a identidade organiza 
significados e permite a negociação de estilos de vida em meio à multiplicidade atual de possibilidades. $\mathrm{O}$ autor propõe três posicionamentos:

a) Identidade de resistência: leva à formação de comunidades como forma de resistência coletiva à desintegração diante de um contexto que impõe certas lógicas como a da flexibilização sociolaboral. Busca referência e proteção em grupos de iguais, sendo a identidade uma maneira de reafirmar seu lugar no mundo, impedido pelas lógicas dominantes, também definida como política de identidade;

b) Identidade legitimadora: leva à identificação com as formas sociolaborais dominantes, gerando um movimento de resignação e adaptação constante da identidade;

c) Identidade de projeto: busca de uma tentativa de negociar a identidade para que ela não seja nem uma resistência, nem uma adaptação à lógica vigente, mas, antes, uma síntese possível que leve em conta tanto a pessoa quanto a sociedade.

Para o autor, há uma dinâmica das identidades e nenhuma delas é uma essência permanente, nem "encerra, per se, valor progressista ou retrógrado se estiver fora de seu contexto histórico" (Castells, 1997, p. 24), entretanto se constituem nos principais retratos possíveis das construções identitárias na contemporaneidade.

\section{Alain Touraine}

Touraine (1998) aponta o enfraquecimento dos controles culturais e sociais, das fronteiras da normatividade e das mediações sociopolíticas, geradas pela dissociação entre economia (mundo instrumental) e cultura (mundo simbólico), como fenômenos que dificultariam a formação do laço social e das identidades. Faz o seguinte questionamento: seria possível a construção de identidades na sociedade globalizada marcada pela flexibilização sociolaboral?

$\mathrm{O}$ autor afirma que temos como possibilidades atuais quatro saídas para as construções identitárias, que estariam determinadas por quatro posições relacionais diante do mundo:

\section{a) Identidade}

comunitária: nostalgia do passado e fechamento em comunidades incomunicáveis que se relacionam com o mundo de forma instrumental, sem estabelecer vínculo, o que só aconteceria no interior de sua comunidade de iguais;

b) Identidade moderna: retorno à coletividade e exclusão da diferença, reforçando os controles normativos generalizantes (modelos sociais passados);

c) Identidade pós-moderna: aceitação da dissociação entre identidade (mundo simbólico de significados) e instrumentalidade (mundo objetivo da economia), se assumindo como pós- 
moderno e em concordância com a lógica do mercado, regendo a vida sociolaboral, numa total falta de controle sobre si e sobre o outro;

d) Sujeito: construção do projeto pessoal como foco para a combinação entre economia e cultura, sendo a pessoa um ator social capaz de negociar as relações entre EU-OUTRO e chegar às resultantes identitárias. "A transformação de indivíduos em sujeitos resulta da combinação necessária de duas afirmações: a dos indivíduos contra as comunidades, e a dos indivíduos contra o mercado" (Touraine, 1998, p. 17). A posição de sujeito, segundo Touraine (1998, 2001), seria a afirmação da liberdade contra a falta de controle pós-moderno e contra os ditadores comunitários, pois a transformação da pessoa em sujeito pede o reconhecimento do outro, proteções institucionais e comunicação intercultural.

\section{Robert Castel}

Castel (1999, 2009), ao refletir sobre o estado de vulnerabilidade atual que parte das pessoas vive, busca compreender um paradoxo: como seria possível, no mundo contemporâneo, existir como pessoa e dispor de proteções, que dependem da participação em coletivos? A partir desta questão, descreve posições possíveis das pessoas em relação ao mundo em que vivem e deste em relação a elas, gerando algumas formas, que poderíamos chamar de identitárias, apesar do autor não se referir às mesmas desta maneira. São elas:

a) Individualismo coletivo: identificação da pessoa com pequenas sociedades que vivem para si e que asseguram uma identidade social e uma proteção máxima, encasteladas em comunidades que tendem ao fechamento;

b) Coletivismo: busca de uma posição em que as referências sociolaborais sejam determinantes para a vida das pessoas, numa modelização das relações sociais;

c) Individualismo

moderno: posição que coloca a pessoa como ser moral, independente, autônomo e nãosocial, sendo "senhor de seus empreendimentos, perseguidor de seus interesses e desafiador de todas as formas coletivas de enquadramento" (Castel, 1999, p. 596-597), embora permaneça solitário e desprotegido, minado pela nãoseguridade e pela ausência de proteções (chamado, também, de empreendedor). Julga ter tudo, por isso não se sente preso às relações sociais: se utiliza das relações sociais para si, não para ser limitado ou enquadrado por elas (Castel, 2009);

d) Individualismo

negativo: marcado pela precariedade permanente e pela dificuldade extrema das pessoas em serem o que aspiram ser, pois é produto do 
enfraquecimento ou perda das referências sociolaborais. Tem como traço comum um individualismo por falta de referências, não por excesso de investimentos subjetivos, ou seja, se forma um individualismo por desagregação do enquadramento coletivo e não por uma afirmação de si.

Castel (2009) aponta que as pessoas têm vivido, em sua maioria, polarizadas entre duas posições: pessoa pelo excesso, que é uma posição definida pelo excesso de subjetividade, individualismo e pela sensação de não estar preso ao social, sendo a relação social um instrumento para a construção pessoal; e pessoa pela falta, que é uma posição definida pela falta de laços, suportes, proteções e inscrições sociais, não pelo desejo da pessoa, mas por uma impossibilidade social, que a coloca num estado de precariedade permanente e sem meios de se constituir em ser social, apesar de continuar a sê-lo.

\section{Stuart Hall}

Hall (2003) aponta que há uma crise das identidades, pois "as velhas identidades, que por tanto tempo estabilizaram o mundo social, estão em declínio, fazendo surgir novas identidades e fragmentando o indivíduo moderno, até aqui visto como um sujeito unificado" (p. 7). Os quadros de referência, que forneciam às pessoas uma ancoragem estável no mundo social, estão abalados, deixando-as sem um claro sentido de si e causando uma dupla e simultânea descentração dos seus lugares no mundo social e de si mesmos. Apesar disso, não há uma substituição total de um modelo social e identitário estável e permanente para um outro modelo instável e contingencial, mas, antes, uma transição na qual operam os dois modelos em conjunto, como já apontado por Santos (1995).

Quais seriam as possibilidades identitárias do século XXI? Na tentativa de responder a esta pergunta, Hall (2003) sugere três concepções distintas: sujeito do Iluminismo, sujeito sociológico e sujeito pós-moderno. Vejamos com mais detalhe cada uma delas.

a) Sujeito do Iluminismo: concepção baseada na ideia de ser humano marcado pelo total centramento e unicidade em torno de si mesmo, sendo a identidade permanente e encerrada num padrão singular;

b) Sujeito sociológico: concepção introdutora da sobredeterminação mútua entre pessoa e mundo social na construção da identidade, que sofre fortes influências desta relação a qual "estabiliza tanto os sujeitos quanto os mundos culturais que eles habitam, tornando ambos reciprocamente mais unificados e predizíveis" (Hall, 2003, p. 12);

c) Sujeito pós-moderno: não há nem uma unificação, nem uma 
permanência na identidade, que é fragmentada, provisória e instável, com extrema dificuldade de se estabilizar, numa celebração móvel da vida social, deixando a pessoa sem uma referência segura a qual se guiar - à deriva, como diria Sennett (1998).

Com a apresentação das reflexões acerca da identidade de cinco grandes pensadores contemporâneos, será realizada uma aproximação teórica entre eles, na tentativa de traçar um panorama do que tem acontecido no mundo sociolaboral contemporâneo, cientes de todos os riscos epistemológicos e metodológicos possíveis decorrentes desta operação.

\section{Síntese dos autores: construções}

\section{identitárias contemporâneas no trabalho}

A partir da análise das reflexões e ideias apresentadas, pode-se vislumbrar a possibilidade de aproximação dos autores citados, que parecem estar analisando, cada um a sua maneira, a realidade sociolaboral atual de forma muito semelhante. E, sinteticamente, foi possível configurar quatro alternativas atuais de construções identitárias (nostalgia, fechamento, instrumentalidade e possibilidade, conforme aparece sistematizado na Tabela 3 , em anexo), como resultado de aproximações e relações genéricas possíveis entre os cinco pensadores discutidos no presente texto (Touraine, Dubar, Castells, Castel e Hall). Estas propostas são fruto das relações atuais entre pessoa e mundo sociolaboral, que situam as pessoas em posições diferenciadas e indicam estratégias de ação distintas, colocadas em prática por elas no espaço público coletivo, visando o vínculo, a ação e o reconhecimento sociolaboral. Vejamos, agora, cada uma em separado.

\section{a) Fechamento}

As construções identitárias seriam sobredeterminadas por uma demanda de pertencimento a um coletivo protetor, sendo sua característica central a referência ou a resistência, numa tentativa de ensimesmamento em comunidades delimitadas, definidas pelos ofícios desempenhados ou pelas identidades profissionais tradicionais. Estão apoiadas na autoridade de um grupo de referência que protegeria a relação pessoa-trabalho.

São trabalhadores que buscam proteção em sindicatos ou, então, em suas áreas específicas de atuação, não fazendo nenhuma concessão. Por exemplo, trabalhadores metalúrgicos que perderam seus empregos e não aceitam outra possibilidade de trabalho a não ser voltar a trabalhar como metalúrgico, ou então psicólogos que trabalham na área de gestão de pessoas desempenhando intervenções específicas da área psicológica, como 
recrutamento e seleção e que, ao receber uma promoção para se tornarem gerentes do setor que atuam, não aceitam, por acharem não se tratar de um trabalho de psicólogo.

São construções identitárias nomeadas de individualismo coletivo (Castel, 1999), identidade de resistência (Castells, 1997), formas identitárias comunitárias reflexivas ou culturais (Demazière \& Dubar, 2006), sujeito do Iluminismo (Hall, 2003) e identidade comunitária (Touraine, 1998).

\section{b) Nostalgia}

Seriam construções identitárias embasadas no modelo moderno de identidade, como modelo de identificação socialmente construído, pelo qual as pessoas moldam suas próprias identidades, numa relação de dependência institucional. O desejo é à volta a uma ordem passada na qual havia instituições normativas geradoras de modelos e estruturas hegemônicas, que ofereciam segurança e vinculação a um sistema de trabalho reconhecido e estável. A busca pelo emprego público, por exemplo, seria uma tentativa atual de manutenção da ordem hegemônica anterior e uma vida com um pouco mais de estabilidade e permanência.

São construções identitárias nomeadas de coletivismo (Castel, 1999), identidade legitimadora (Castells, 1997), formas identitárias societárias estatutárias (Demazière \& Dubar, 2006), sujeito sociológico (Hall, 2003) e identidade moderna (Touraine, 1998).

c) Possibilidade

As construções identitárias seriam geradas na relação constante entre pessoa e mundo do trabalho, instalando a ação sobre o mundo como estratégia de construção de si e da relação com o outro, numa possibilidade de se posicionar ativamente no jogo político da construção social através da realização de projetos individualizados, mas legitimados socialmente, pois a pessoa se localizaria de forma intermediária entre a estabilidade permanente de uma estrutura hegemônica e genérica e a transformação incessante de estruturas singulares não-intercambiáveis. Nesse sentido, aproveita da estabilidade da identidade moderna (Touraine, 1998), mas não fica alienado nela, podendo, concretamente, superar parcialmente sua limitação e restrição para, através de projetos psicossociais, fazer a gestão das relações com o social e construir lugares próprios e, ao mesmo tempo, legitimados socialmente.

Segundo Dubet (1996), a unicidade das significações da vida social não estaria no sistema, mas, antes, estaria parcialmente no trabalho de construção do ator social (a concepção de sujeito de 
Touraine, 1998), através do qual constrói sua experiência social ("condutas organizadas por princípios estáveis, mas heterogêneos", Dubet, 1996, p. 93).

Há várias lógicas do sistema social e de ação que são escolhidas de acordo com a relação da pessoa sobre o mundo, sendo que não haveria mais um centro ou uma lógica única ou básica. Um exemplo desta estratégia pode ser visto em profissionais que têm o ponto de partida de sua atuação no mundo do trabalho na identidade profissional, entretanto reconstróem estas atuações, negociando ações e modalidades de intervenção laboral, incorporando novos elementos à sua identidade profissional, o que acarreta mudanças em sua identidade profissional particular e na identidade profissional genérica de dada categoria.

O psicólogo que, no exemplo anterior, não aceita ser gerente de gestão de pessoas, se construísse uma identidade de projeto (Castells, 1997), não só aceitaria tal promoção, como tentaria modificar a atuação de gerente para aproximá-la mais da atuação do psicólogo, transformando o particular de sua intervenção e buscando atingir o coletivo de sua categoria profissional. São construções identitárias nomeadas de individualismo moderno (Castel, 1999), identidade de projeto (Castells, 1997), formas identitárias societárias narrativas (Demazière \& Dubar,
2006) e sujeito (Touraine, 1998).

d) Instrumentalidade

Haveria, aqui, uma dificuldade de estabelecimento da construção identitária, pois a pessoa visaria somente uma adaptação às demandas do mundo do trabalho, sem escolha, nem vínculo, nem compromisso. É caracterizada por se constituir numa adaptação identitária instrumental aos processos de trabalho, marcada pela não-permanência, transitoriedade e uso instrumental da relação com o mundo (estratégia identitária de difusão adaptativa), fixando uma crise do laço social (Dubar, 2000), apesar de ser uma construção psicossocial.

Poderíamos citar como exemplo, parte dos chamados consultores, que em geral adaptam-se as necessidades dos clientes, realizando as tarefas contratadas, não gerando história e nem mesmo construção de vínculos seja com a tarefa, seja com a empresa ou com as pessoas envolvidas. Uma tática que aprisiona as pessoas na temporalidade presente e nas circunstâncias, reduzindo a ação ao momento, sem chance de apropriação, potencializando um processo de desidentidade (Touraine, 2001) ou a criação de um fantasma da inutilidade (Sennett, 2006). São construções identitárias nomeadas de individualismo negativo (Castel, 1999), formas identitárias 
de difusão adaptativa (Demazière \& Dubar, 2006), sujeito pós-moderno (Hall, 2003) e identidade estratégica ou pósmoderna (Touraine, 1998).

Esta proposta de tipologia encontra respaldo nas reflexões dos teóricos citados na Tabela 3 e, como toda tipologia, abarca possibilidades de mudança de uma configuração identitária para outra e envolve gradações possíveis entre elas, sendo que, provavelmente, a maior parte das pessoas não apresente uma forma pura de uma destas configurações, que carecem de mais pesquisa empírica para serem consolidadas.

\section{Considerações Finais}

O mundo moderno das normas vem sofrendo fraturas e rupturas em seu tecido sociolaboral, que tem instalado, gradativamente, novas lógicas de organização social, principalmente pela multiplicação dos referentes sociais (outros generalizados), necessários para as construções identitárias. Se, de um lado há maior flexibilidade e possibilidade potencial de operar transformações sociais e menor hegemonia de padrões, de outro há menos garantias, mais insegurança e mais solidão pela ruptura dos padrões mais coletivos. Assim, a identidade deixa de ser apenas uma estrutura homogênea e produto de adaptação a uma ordem social predefinida, para se transformar, parcialmente, em construções identitárias mais heterogêneas, complexas e flexíveis.

De um lado, temos as categorias propostas da nostalgia e do fechamento embasadas numa adaptação a uma estrutura sociolaboral ou grupo socioprofissional predefinidos (foco na dimensão institucional), que reduzem, significativamente, as chances de transformação relacional recíproca pela tentativa de estabilidade e identificação aos quadros identitários constituídos, levando a pessoa a perpetuar a estrutura instituída num projeto de vida no trabalho com base na estabilidade subjetiva ou cristalização identitária (Guichard, 2000).

Por outro, temos as categorias propostas da instrumentalidade e da possibilidade como construções relacionais de transformação recíproca, geradoras de sínteses temporárias focadas na relação pessoa-trabalho, como um modelo transitório ou identidade vicária (Guichard, 2000). Ambas são construções relacionais, mas, enquanto a possibilidade geraria uma construção identitária transformadora por fornecer instrumentos para ação e transformação sobre e no mundo sociolaboral, conferindo sentido e constituição de uma história para a pessoa, a instrumentalidade, por outro lado, marcada pela mudança constante e pela não permanência, impossibilitaria, muitas 
vezes, a geração de sentido ou história no trabalho.

Concluindo, a contemporaneidade, segundo a categorização postulada, estruturaria dois caminhos: o caminho do projeto de ajustamento ou adaptação mais definidos e estáveis (categoria do fechamento e da nostalgia) ou a ação de construção relacional entre pessoa-mundo do trabalho (categoria da possibilidade e da instrumentalidade), instaurando o jogo de reconhecimento sociolaboral que gera, atualmente, oportunidades de maior autonomia identitária, impossibilidade identitária (desidentidade) ou o retorno à identidade moderna.

Se, antes, havia uma dificuldade de escapar da alienação identitária por uma adaptação a uma ordem de normas hegemônicas e predefinidas, agora a possibilidade de superação desta alienação existe pela construção psicossocial de si num mundo em transição, entretanto há chance de desindentidade também, o que amplia posições no jogo político do reconhecimento sociolaboral, mas também produz situações de maior vulnerabilidade identitária. São necessários, contudo, estudos para verificação destas hipóteses na realidade brasileira. 
Tabela 1

Processo de Construção Identitária, segundo Dubar (1997)

\begin{tabular}{|c|c|}
\hline \multicolumn{2}{|c|}{$\begin{array}{l}\text { MODOS DE ARTICULAÇÃO ENTRE DOIS PROCESSOS IDENTITÁRIOS } \\
\text { HETEROGÊNEOS }\end{array}$} \\
\hline PROCESSO RELACIONAL & PROCESSO BIOGRÁFICO \\
\hline Identidade para o outro (reconhecimento) & Identidade para si (autoconhecimento) \\
\hline $\begin{array}{l}\text { Atos de atribuição (aquilo que dizem que } \\
\text { você é) }\end{array}$ & Atos de pertença (aquilo que você diz que é) \\
\hline $\begin{array}{l}\text { Transação objetiva entre identidade atribuída } \\
\text { e identidade assumida }\end{array}$ & $\begin{array}{l}\text { Transação subjetiva entre identidade herdada } \\
\text { e identidade visada }\end{array}$ \\
\hline $\begin{array}{l}\text { Resultado: } \\
\text { Reconhecimento ou não-reconhecimento } \\
\text { sociolaboral }\end{array}$ & $\begin{array}{l}\text { Resultado: } \\
\text { Produção (ruptura identitária) ou reprodução } \\
\text { (continuidade identitária) }\end{array}$ \\
\hline
\end{tabular}

Tabela 2

Modos Genéricos de Identificação ao Mundo do Trabalho na Contemporaneidade (adaptado de Demazière \& Dubar, 2006)

\begin{tabular}{|l|l|l|}
\hline \multirow{2}{*}{ Processo relacional } & Formas societárias & Formas comunitárias \\
\hline \multirow{2}{*}{ Processo biográfico } & $\begin{array}{l}\text { Forma estatutária } \\
\text { Identidade de empresa } \\
\text { (Dependência institucional) }\end{array}$ & $\begin{array}{l}\text { Forma reflexiva } \\
\text { Identidade de ofício } \\
\text { (Referência) }\end{array}$ \\
\hline & $\begin{array}{l}\text { Forma narrativa } \\
\text { Identidade de rede } \\
\text { (Projeto) }\end{array}$ & $\begin{array}{l}\text { Forma cultural } \\
\text { Identidade de grupo } \\
\text { (Resistência) }\end{array}$ \\
\cline { 2 - 3 } & Difusão adaptativa & \\
\hline
\end{tabular}


Tabela 3

Proposta das Construções Identitárias Contemporâneas no Trabalho

\begin{tabular}{|c|c|c|c|c|c|c|}
\hline \multicolumn{2}{|l|}{$\begin{array}{l}\text { Claude } \\
\text { Dubar }\end{array}$} & $\begin{array}{l}\text { Manuel } \\
\text { Castells }\end{array}$ & $\begin{array}{l}\text { Alain } \\
\text { Touraine }\end{array}$ & $\begin{array}{l}\text { Stuart } \\
\text { Hall }\end{array}$ & $\begin{array}{l}\text { Robert } \\
\text { Castel }\end{array}$ & $\begin{array}{l}\text { SAÍDAS } \\
\text { IDENTITÁRIAS }\end{array}$ \\
\hline \multirow{2}{*}{$\begin{array}{l}\text { Forma } \\
\text { comu- } \\
\text { nitária }\end{array}$} & $\begin{array}{l}\text { Forma } \\
\text { identitária } \\
\text { reflexiva }\end{array}$ & \multirow[t]{2}{*}{$\begin{array}{l}\text { Identidade } \\
\text { de } \\
\text { resistência }\end{array}$} & \multirow[t]{2}{*}{$\begin{array}{l}\text { Identidade } \\
\text { comuni- } \\
\text { tária }\end{array}$} & \multirow[t]{2}{*}{$\begin{array}{l}\text { Sujeito do } \\
\text { Iluminismo }\end{array}$} & \multirow[t]{2}{*}{$\begin{array}{l}\text { Individua- } \\
\text { lismo } \\
\text { coletivo }\end{array}$} & \multirow[t]{2}{*}{ Fechamento } \\
\hline & $\begin{array}{l}\text { Forma } \\
\text { identitária } \\
\text { cultural }\end{array}$ & & & & & \\
\hline \multirow{2}{*}{$\begin{array}{l}\text { Forma } \\
\text { socie- } \\
\text { tária }\end{array}$} & $\begin{array}{l}\text { Forma } \\
\text { identitária } \\
\text { estatutária }\end{array}$ & $\begin{array}{l}\text { Identidade } \\
\text { legitima- } \\
\text { dora }\end{array}$ & $\begin{array}{l}\text { Identidade } \\
\text { moderna }\end{array}$ & $\begin{array}{l}\text { Sujeito } \\
\text { sociológico }\end{array}$ & $\begin{array}{l}\text { Coleti- } \\
\text { vismo }\end{array}$ & Nostalgia \\
\hline & $\begin{array}{l}\text { Forma } \\
\text { identitária } \\
\text { narrativa }\end{array}$ & $\begin{array}{l}\text { Identidade } \\
\text { de projeto }\end{array}$ & Sujeito & & $\begin{array}{l}\text { Individua- } \\
\text { lismo } \\
\text { moderno }\end{array}$ & Possibilidade \\
\hline \multicolumn{2}{|c|}{$\begin{array}{l}\text { Forma identitária de } \\
\text { difusão adaptativa }\end{array}$} & & $\begin{array}{l}\text { Identidade } \\
\text { estratégica } \\
\text { ou pós- } \\
\text { moderna }\end{array}$ & $\begin{array}{l}\text { Sujeito } \\
\text { Pós- } \\
\text { moderno }\end{array}$ & $\begin{array}{l}\text { Individua- } \\
\text { lismo } \\
\text { negativo }\end{array}$ & Instrumentalidade \\
\hline
\end{tabular}

\section{Referências}

Antunes, R. (1999). Os sentidos do trabalho: ensaio sobre a afirmação e a negação do trabalho. São Paulo: Boitempo.

Barbier, J.-M. (1996). Elaboração de projectos de acção e planificação. Porto: Porto.
Blanch, J. M. (Org.). (2003). Teoría de las relaciones laborales. Desafíos. Barcelona: UOC.

Castel, R. (1999). As metamorfoses da questão social: uma crônica do salário (2a ed.). Petrópolis, RJ: Vozes.

Castel, R. (2009). La montée des incertitudes: travail, protections, 
statut de l'individu. Paris: Éditions du Seuil.

Castells, M. (1997). O poder da identidade (A era da informação: economia, sociedade e cultura) - II. São Paulo: Paz e Terra.

Certeau, M. (1994). A invenção do cotidiano: 1. Artes de fazer. Petrópolis, RJ: Vozes.

Coutinho, M. C. (2009). Sentidos do trabalho contemporâneo: trajetórias identitárias como estratégia de investigação. Cadernos de Psicologia Social do Trabalho, 12 (2), 189-202.

Coutinho, M. C.; Krawulski, E., \& Soares, D. H. P. (2007). Identidade e trabalho na contemporaneidade. Psicologia e Sociedade, 19 (1) especial, 29-37.

Demazière, D., \& Dubar, C. (2006). Trajetórias profissionais e formas identitárias: uma teorização. Em N. A. Guimarães, \& H. Hirata (Orgs.), Desemprego: trajetórias, identidades, mobilizações (pp. 165-187). São Paulo: SENAC.

Dubar, C. (1997). A socialização: construção das identidades sociais e profissionais. Porto: Porto.

Dubar, C. (2000). La crise des identité: l'interprétation d'une mutation. Paris: PUF.

Dubet, F. (1996). A sociologia da experiência. Lisboa: Instituto Piaget.
Fischer, G.-N. (1996). Os conceitos fundamentais da psicologia social. Lisboa: Instituto Piaget.

Guichard, J. (2000). Cadres et formes identitaires vicariantes et pratiques en orientation. L'Orientation Scolaire et Professionnelle, 29 (1), 181-212.

Hall, S. (2003). A identidade cultural na pós-modernidade. Rio de Janeiro: DP \& A.

Kraus, W. (1998). La fin des grands projets: le développement de l'identité dans le champ du travail comme navigation a vue. L'Orientation Scolaire et Professionnelle, 27 (1), 105-121.

Lallement, M. (2007). Le travail: une sociologie contemporaine. Paris: Gallimard.

Lukács, G. (1982). The ontology of social being: labour. London: Merlin Press.

Malo, E. M. (2007). Las dimensiones fragmentaria y performativa de las subjetividades de clase. Universitas Psychologica, 6 (1), 11-25.

Marcia, J. E. (1966). Development and validation of ego identity status. Journal of Personality and Social Psychology, 3, 551-558.

Mead, G. H. (1953). Espiritu, persona y sociedad. Buenos Aires: Paidós.

Pelletier, D. (2001). S'orienter dans un monde incertain. Em Pelletier, D. 
(Org.), Pour une approache orientante de l'école québécoise (pp. 7-23). Québec: Septembre.

Ribeiro, M. A. (2009). A trajetória da carreira como construção teóricoprática e a proposta dialética da carreira psicossocial. Cadernos de Psicologia Social do Trabalho, 12 (2), 203-216.

Sainsaulieu, R. (1988). L'Identité au travail. Paris: Presses de la FNSP.

Santos, B. S. (1995). Pela mão de Alice: o social e o político na pósmodernidade. São Paulo: Cortez.

Sennett, R. (1998). A corrosão do caráter. Rio de Janeiro: Record.

Sennett, R. (2006). A cultura do novo capitalismo. Rio de Janeiro: Record.

Touraine, A. (1998). Poderemos viver juntos? Iguais e diferentes. Petrópolis, RJ: Vozes.

Touraine, A. (2001). Découvrir des projets personnels dans un monde en changement (CD ROM). Em Actes du Congrès Mondial de L'AIOSP, 50. Paris: UNESCO/Sorbonne.

Marcelo Afonso Ribeiro Doutor em Psicologia Social; Mestre em Psicologia do Desenvolvimento Humano; Docente do Departamento de Psicologia Social e do Trabalho do Instituto de Psicologia da Universidade de São Paulo, onde coordena o CPAT (Centro de Psicologia Aplicada ao
Trabalho); faz pesquisas na interface trabalho, identidade, desemprego e carreira. Presidente da Associação Brasileira de Orientação Profissional (2009-2011).

E-mail: marcelopsi@usp.br

\section{Maria Conceição Coropos Uvaldo}

Mestre e Doutora em Psicologia Social; Especialista em Orientação Profissional; Psicóloga do Setor de Orientação Profissional do Instituto de Psicologia da Universidade de São Paulo; Docente do Instituto Sedes Sapientiae-SP; faz pesquisas na interface trabalho, identidade e carreira. Diretora da Associação Brasileira de Orientação Profissional (2009-2011).

E-mail: mcuvaldo@usp.br 